\title{
ARE PROFESSIONAL SKI INSTRUCTORS IN BULGARIA READY TO WORK WITH PEOPLE WITH DISABILITIES?
}

\author{
Boyana Kotseva \\ National Sports Academy "Vassil Levski", Sofia, Bulgaria
}

\begin{abstract}
Adapted skiing for people with disabilities in Bulgaria is recognizable as a motor activity thanks to Special Olympics $B G$, but it is only in 2016 when they become accessible for everyone, and very few are those who can practice regularly. A key factor for a long-term sustainable development is collecting information regarding the attitude of Bulgarian ski instructors towards working with people with disabilities (Mayhew, 2017). Bulgaria has one of the best ski resorts in Eastern Europe and hosts different world alpine sports events from the International Ski Federation. The development potential for adapted skiing on a national level (Kotseva, Zgurovski, 2014) is indisputable and a study was conducted among the professional ski instructors, giving valuable information on building a national strategy for adapted skiing. Results show that a great number of the professional teachers are willing to work with people with disabilities but feel uncertain due to the lack of adapted methodologies.
\end{abstract}

Key words: adapted ski, ski instructors, disabilities, Bulgaria

\section{INTRODUCTION}

Adapted physical activities and sports in Bulgaria have developed in the past two decades. We are observing a trend in the popularization and rising number of different sports and activity events since 2016. Adapted winter sports like 'adapted skiing' are still making their way through, in order to give people with disabilities the opportunity to be physically active and spend more time outdoors during the winter season. This adapted motor activity is not well-known in Bulgaria but has gained some familiarity thanks to some one-day-events or NGO's as ParaKids and Special Olympics that support this type of activities. However, they suffer from a lack of well-prepared individuals that would work in this shpere.

\section{Aim and Objectives}

This study was held among the professional guild for the first time, and aims to understand the attitude of Bulgarian professional ski instructors towards working with people with disabilities. Analyzing the opinion of the human and pedagogical resources in the sphere of winter sports is a key factor for developing 'adapted skiing' as a service that would give people with disabilities the opportunity to be active during the winter season and to spend more time outdoors. Future studies are needed in order to get a better understanding and optimization of a strategy on a national level.

\section{METHODOLOGY}

For the purpose of this study, an empirical study was conducted with 65 ski instructors (26 women and 39 men) working in 4 different ski resorts. Tests consisted of analyze of the demographic block (gender; qualification; years of professional experience) and a questionnaire, based on Theory of Planned Behavior and semantic differential with a seven-degree answer scale -3 answers with positive degrees, 1 neutral and 3 negative degrees (Ajzen, 1991). The questionnaire has three constructs, compiled from a high number of questions.

\section{RESULTS}

The results show that the ski instructors that took part in the questionnaire have a highly positive attitude towards people with disabilities and interacting with them. There is not a single negative or neutral answer to the question specifically corresponding to this matter, and $88 \%$ of strongly positive answers by the respondents.

The explicit distribution of the results from the first construct of the questionnaire, corresponding to behavioral beliefs, demonstrates the highly positive attitude of ski instructors towards the chance of working with people with disabilities. The demographic data block does not demonstrate considerable differences in answers among the specialists in terms of gender, professional class or work experience. 
Despite the predominantly positive results, respondents show hesitancy about answering questions depicting any possible difficulties in working with people with disabilities. This might be interpreted as a natural reaction against a challenge that requires more effort than the usual job responsibilities, or lack of knowledge in a certain sphere (Braiker, Harriet, 2004).

There are underlying questions in the construct, corresponding to the subjective or normative beliefs, aiming to obtain information regarding the confidence of the ski instructors in directly com- municating and working with people with disabilities (Figure 1). Only $31 \%$ feel absolutely confident in communicating with disabled people, $25 \%$ are neutral, and $34 \%$ have low or moderate confidence. The questionnaire also contains a question looking to gain more insight on the knowledge of professional ski instructors in working with people with disabilities outdoors. Only $14 \%$ of all questionnaire participants consider they have good knowledge in how to teach people with disabilities (Figure 1). We consider this is due to the lack of regulation and adapted methodologies for teaching alpine skiing, and little or no prior experience.

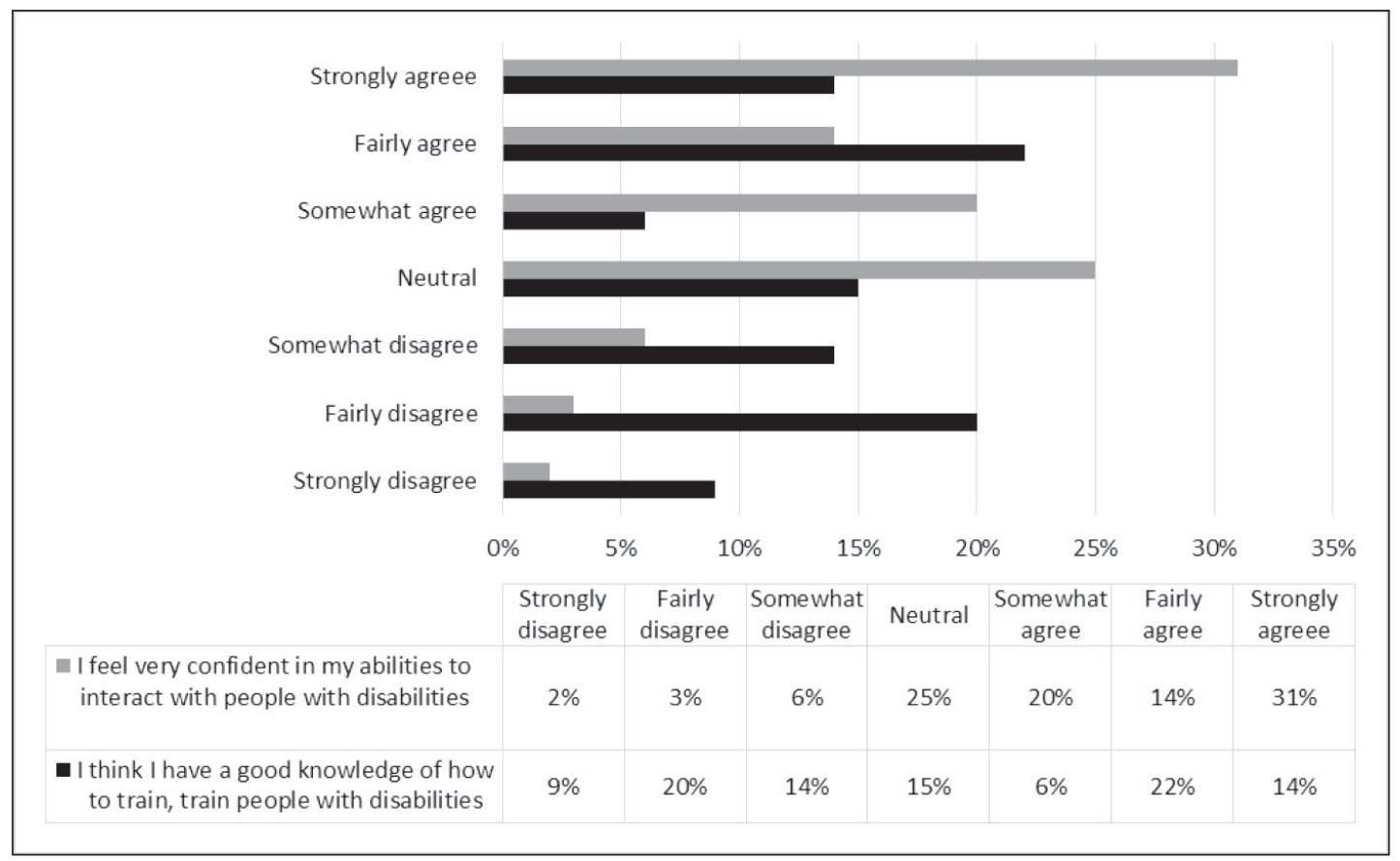

Figure 1. Opinion of Bulgarian professional ski instructors responded to a survey in the winter season 2017/2018

It is also needed to pay attention to the perceived sional skills. Another reason behind these data rebehavioral control in order to predict the intentions and future behavior of the professional ski instructors (Ajzen, 2002). The study gets more information regarding this matter from the last construct of the survey. It contains questions regarding volunteering initiatives and remuneration for adapted skiing services (skiing lessons for people with disabilities). There is no prevailing opinion among the questionnaire participants that these services have to be paid. Only $17 \%$ of the people disagree completely, other $20 \%$ are neutral, $24 \%$ more or less agree, while as many as $26 \%$ are firm that this type of labor has to be paid. We consider this might stem from the fact that ski instructors are highly occupied during the winter season. On the other hand, this service requires more knowledge and professults could also be certain moral beliefs (Stanford Encyclopedia of Philosophy, 2014).

\section{DISCUSSION}

In summary, there is no data for ski instructors with any specific experience in working with people with disabilities in the sphere of winter sports. That is why periodical studies on this topic could give more insights on this matter.

\section{CONCLUSIONS}

Professionals are available and ready, but a pedagogical technique and a reliable national strategy for development of adapted skiing discipline needs to be provided in order to deliver a long-term sustainable service in Bulgaria. 


\section{REFERENCES}

Ajzen, I. (1991). The theory of planned behavior. Organizational Behavior and Human Decision Processes. Open University Press, England, pp. 141

Ajzen, I. (2002). Perceived Behavioral Control, Self-Efficacy, Locus of Control, and the Theory of Planned Behavior. Journal of Applied Social Psychology, vol.32, pp. 673

Braiker, HB. (2004). Who's Pulling Your Strings? How to Break The Cycle of Manipulation?, McGraw Hill Professional, ISBN 0-07-144672-9, pp.98

Kotseva, B., Zgurovski. K. (2014). Management of a sport event for adapted skiing, Proceedings of the FIEP Congress and International Scientific Congress "Sport, Stress, Adaptation”, Bulgaria, Sofia, Bulgaria, pp. 122
Mayhew, R. (2017). The Important Factors of Human Resource Management, The Journal of Management, Texas Christian University, US \& University of Warwick, UK, pp. 2

Stanford University, "The Definition of Morality”. Stanford Encyclopedia of Philosophy. Stanford University. Retrieved 22 March 2014.

Corresponding author:

Boyana Kotseva National Sports Academy "Vassil Levski", 21, Acad. Stefan Mladenov, str. Sofia, Bulgaria and Co-founder of ParaKids E-mail: kotseva.boyana@gmail.com; parakids.bg@gmail.com 